\title{
Investigation of Thermal Parameters Effects on the Microstructure, Microhardness and Microsegregation of Cu-Sn alloy Directionally Solidified under Transient Heat Flow Conditions
}

\author{
Késsia Gomes Paradela ${ }^{a}$ Luis Antônio de Souza Baptista ${ }^{a}$ Roberto Carlos Sales ${ }^{a}$, Paulo Felipe Junior ${ }^{a}$, \\ Alexandre Furtado Ferreira ${ }^{a *(1)}$ \\ a Programa de Pós-Graduação em Engenharia Metalúrgica, Universidade Federal Fluminense, Volta \\ Redonda, RJ, Brasil
}

Received: March 21, 2019; Revised: April 16, 2019; Accepted: June 26, 2019

\begin{abstract}
The microstructure and mechanical properties of cast materials are strongly dependent on the thermal history during solidification process. The global casting industry has faced major challenges, i.e., customers increasingly demand completely finished cast parts as well as complexity of casting alloys are rising. Therefore, the previous knowledge the solidification conditions effects on the ascast ingot microstructure and mechanical properties resulting is very useful in the casting industry in order to improve the casting quality. In this present paper, the thermal parameters effects on the microstructure, microhardness and microsegregation of a Cu- $20 \mathrm{wt} . \% \mathrm{Sn}$ alloy under transient heat flow conditions were experimentally investigated. The experimental observations indicate that the tertiary dendritic arm spacing $\left(\lambda_{3}\right)$, microsegregation and microhardness are affected by the thermal parameters (solidification speed and cooling rate). Solidification speed $\left(S_{S}\right)$ associated with increasing cooling rate $\left(R_{C}\right)$ are found to contribute to the decreasing tertiary dendritic arm spacing $\left(\lambda_{3}\right)$. However, cooling rates from $11.36{ }^{\circ} \mathrm{C} / \mathrm{s}$ to $0.65{ }^{\circ} \mathrm{C} / \mathrm{s}$ were not found to affect significantly the microhardness along the ingot length. The solute concentration $(S n)$ in solid region were calculated by Scheil and Clyne-Kurz equation, and used in the predictions of microsegregation profiles. The results calculated by equations, have shown deviations from the experimental data. It is well known that it is very difficult to calculate these concentration profiles using the equilibrium partition coefficient, since frequently castings solidify under non-equilibrium conditions and the solidification process is known as non-equilibrium solidification. For this reason, effect of solidification speed $\left(S_{S}\right)$ was considered into equations through effective partition coefficient $\left(\boldsymbol{k}_{e f}\right)$ that has been determined for the range of solidification speed experimentally examined between 0.19 and $0.89 \mathrm{~mm} / \mathrm{s}$. However, results calculated by Scheil and Clyne-Kurz equation using the effective partition coefficient $\left(\boldsymbol{k}_{e f}\right)$, yielded discrepancies from the experimental results. Because of its deviations between calculated and experimental data, an experimental equation with effective partition coefficient $\left(\boldsymbol{k}_{e f}\right)$, is considered in present work, showing an excellent agreement with the experimental data.
\end{abstract}

Keywords: binary alloy, solidification, microstructure, microsegregation, microhardness.

\section{Introduction}

The $\mathrm{Cu}-\mathrm{Sn}$ alloys are well known and frequently used in industries automotive and electronics due to their good thermal conductivity, high strength, good weldability and excellent wear resistance ${ }^{1-3}$. The $\mathrm{Cu}-\mathrm{Sn}$ alloys have a wide solidification interval, which make them susceptible to segregation during the solidification process. The effect of microsegregation on casting quality has been investigated over the decades by theoretical and experimental models ${ }^{4-16}$. Ferreira et al. ${ }^{4}$ used a numerical model to the prediction of microsegregation and dendritic arm spacing during solidification of hypoeutectic $\mathrm{Al}-\mathrm{Cu}$ alloys. It is shown by performing comparisons between experimental microsegregation results and theoretical models with equilibrium partition coefficient, a reasonable agreement between them.
In said work, because of the increase in copper concentration, the dendrite becomes narrower and the secondary arms are not well developed, and that was caused by solute enrichment at the growth interface and reduction in solidification speed. Baptista et al. ${ }^{16}$, in order to study the changes in the dendritic arm spacing and microsegregation, used a unidirectional vertical cooling apparatus. It was shown that the increase in the copper content induces a decreasing in the solidification speed $\left(S_{S}\right)$ and thickening effect on the tertiary dendritic arm spacing $\left(\lambda_{3}\right)$. The microsegregation profiles between adjacent tertiary dendritic arms $\left(\lambda_{3}\right)$ revealed that both solutes profiles increase gradually from the center of an arm toward the center of the interdendritic region. The profiles of copper microsegregation were shown to move upwards with the solidification speed $\left(S_{S}\right)$. Despite the commercial importance of $\mathrm{Cu}$-Sn alloys, few studies have been conducted on the effects of solidification thermal parameters concerning the

*e-mail: alexandrefurtado@id.uff.br 
microsegregation, dendritic arm spacing and mechanical properties of the solidified material. Kumoto et al. ${ }^{12}$ have carried out solidification experiments with a $\mathrm{Cu}-4.7 \mathrm{wt} . \% \mathrm{Sn}$ alloy using a two-phase zone continuous casting apparatus. The results have shown a fifteen-fold corrosion resistance improvement and a $12.2 \%$ better conductivity when compared with a conventional casting procedure, authors also observed a significant tensile strength and ductility improvements. Kohler et al. ${ }^{17}$ examined the transition between different geometrical arrangements in the lamellar structures at low grown rate of peritectic $\mathrm{Cu}-\mathrm{Sn}$ alloys. They found growth competition mechanisms $(\alpha+\beta$ band), which are similar to those involved in the formation of islands. Rettenmayr and Stier $^{18}$ analyzed the evolution of the microstructure of the $\mathrm{Cu}$-Sn alloy near the metatectic, they found that the effects of anisotropy play no role during the microstructural evolution. However, metatectic reaction was observed primarily between the thick structures. There is a need to improve the understanding of the combination of solidification conditions and microsegregation during alloys solidification. Non-equilibrium solidification conditions lead to significant variations in solidification speed and microsegregation profiles at different positions in the casting, which in turn can lead to significant modifications in the mechanical properties resulting from solidification process. The main reason of microsegregation is the thermodynamics of solidification, and hence, the partition coefficient $\left(\boldsymbol{k}_{e q}\right)$. In most cases for $\boldsymbol{k}_{e q}<1$, the solutes tend to remain in the liquid phase during solidification, thus, the solute concentration increase in the liquid during solidification process. Theoretical models for analysis of microsegregation are based on equilibrium and non-equilibrium conditions. These models are widely considered in the literature to compared with experimental results. However, inaccuracies from these models were presented and discussed by Ferreira et al. ${ }^{11}$ and Baptista et al. ${ }^{19}$ and some corrections were implemented to achieve a better prediction with experimental data. The main correction included the consideration of solidification speed in calculations of partition coefficient. Though the efforts have been devoted to this aim, some discrepancies remain between theorical models and experimental data thus, experimental equations based on a best-fit curve to the experimental solute profiles, have been proposed, which showed to adjust well to the experimental data, as discussed by Baptista et al. ${ }^{16}$. The present work analyses the thermal variables effect on the $\mathrm{Cu}-20$ wt.\% Sn alloy during unidirectional solidification process. The cooling rate $\left(R_{C}\right)$ and solidification speed $\left(S_{S}\right)$ are experimentally determined for each measurement point along the casting, at the moment when material reaches the liquidus temperature, as a general rule, assume that solidification begins in liquidus temperature and ends when it reaches the solidus temperature. The tertiary dendritic spacing $\left(\lambda_{3}\right)$ and Vickers microhardness $\left(M_{d}\right)$ have been measured and correlated with the thermal parameters. The microsegregation phenomenon during the solidification process has been studied based on the well-known Scheil and Clyne-Kurz equation. However, the numerical results were not satisfactory in any case investigated. In order to improving predictions, an empirical equation with effective partition coefficient $\left(\boldsymbol{k}_{e f}\right)$, was adopted in present work.

\section{Experimental Procedure}

Directional solidification has been widely used to produce uniform structures and to allow better control of the solidification ${ }^{7,14,20,21}$. In this present paper, a unidirectional solidification apparatus is adopted, which heat is extracted from bottom of mold by water cooling system. The apparatus is detailed in previous articles ${ }^{7,19}$. The upward solidification system gives more stability in liquid region since it does not induce convection currents during solidification process. In the upward vertical solidification, the solute concentration in the mushy zone and in the overlying melt ahead of the dendritic array is expected to be stable because solute enrichment causes an increase in the melt density ${ }^{22}$. The alloy studied was produced from copper $(99.80 \% \mathrm{Cu})$ and tin $(99.85 \% \mathrm{Sn})$ in a muffle furnace. The chemical composition of the alloy has been measured using fluorescence x-ray spectrometry technique. The temperature mapping during solidification of the $\mathrm{Cu}-20$ wt.\% $\mathrm{Sn}$ alloy, was made using thermocouples positioned at seven different points located at $5,10,15,20,35,45$ and $60 \mathrm{~mm}$ from the refrigerated base. The thermocouples are of the " $K$ " type, with stainless steel jacket, $1.3 \mathrm{~mm}$ in diameter and protected by two layers of refractory paint. These thermocouples were connected to a high-speed data logger and, therefore, able to generate the required real time thermal profiles. The casting with height of $100 \mathrm{~mm}$, was cut for the macro and microstructural analysis. After the solidification experiment, casting was sectioned along its vertical axis, and mechanically polished with abrasive papers and subsequently etched with an acid solution (Ethanol, Ferric chloride and Hydrochloric acid) during $15 \mathrm{~s}^{23}$ in order to reveal the macrostructure. After the macrostructural analysis, selected transverse sections of the solidified specimens at 5, 10, 20,35, 45 and $60 \mathrm{~mm}$ from the mold bottom were polished and etched with a solution of ammonium hydroxide and hydrogen peroxide during $5 \mathrm{~s}$ and then etched with an acid solution (Ethanol, Ferric chloride and Hydrochloric acid) during $3 \mathrm{~s}$ for micrograph examination. The tertiary dendritic spacing $\left(\lambda_{3}\right)$ were measured on the transverse section by averaging the distance between adjacent side branches ${ }^{7,24}$. Dendritic spacing usually refers to the spacing the secondary arms of the dendrites. However, if tertiary arms are present, the spacing will be referred to this one once its smaller dimensions become more significant for the properties of the material, according to Baptista et al. ${ }^{16}$. The microhardness was measured in each sample using a diamond pyramidal indenter and a Shimatzu HMV-G20S 
microhardness tester. About 10 measurements of microhardness have carried out with a load of $19.614 \mathrm{~N}$ during $20 \mathrm{~s}$, for each selected position at the cylinder central region. The microsegregation measurement initiates at the center of a dendritic arm and ends at the midpoint of the interdendritic region between adjacent arms, defining the microsegregation path (Kattamis and Flemings ${ }^{25}$, as shown in Fig. 1.

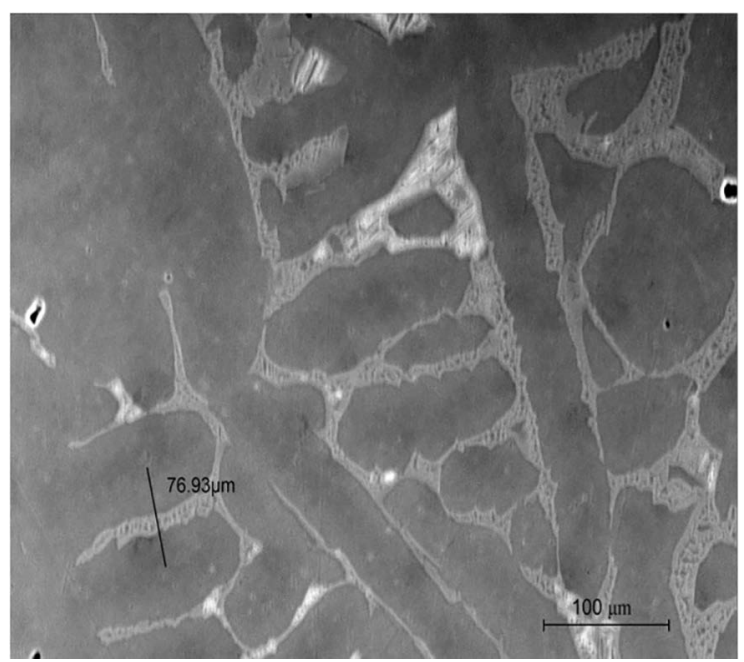

Figure 1. Typical track adopted for measurements of solute microsegregation of the $\mathrm{Cu}-20 \mathrm{wt} . \% \mathrm{Sn}$ alloy.

About 40 concentration measurements were performed for each examined position along the casting, using a JEOL scanning electron microscope model JSM5800LV with a Noran EDS. Analytic equation were used to predict the microsegregation profiles for comparison with the experimental results. The well-known Scheil equation ${ }^{14}$, here adopted, considers no diffusion in the solid, infinite diffusion in the liquid region and thermodynamic equilibrium at the interface, is described by eq. (1):

$$
C_{s}=k_{e q} C_{0}\left(1-f_{s}\right)^{k_{e q}^{-1}}
$$

where, $C_{S}$ is the solute concentration in the solid region, $\boldsymbol{k}_{e q}$ is equilibrium partition coefficient, $C_{0}$ is the initial solute concentration in the alloy and $\mathrm{f}$ s corresponds to the fraction solidified. Clyne and Kurz proposed a microsegregation equation which takes into account back-diffusion in the solid region ${ }^{26}$ :

$$
C_{s}=k_{e q} C_{0}\left[1-\left(1-2 \alpha^{\prime} k_{e q}\right) f_{s}\right]^{\frac{k_{e q} q^{-1}}{1-2 \alpha k e q}}
$$

$\alpha^{\prime}$ is defined by eq. (3):

$$
\begin{gathered}
\alpha^{\prime}=\alpha\left[1-e^{\left(\frac{-1}{\alpha}\right)}\right]-\frac{1}{2} e^{\left(\frac{-1}{2 \alpha}\right)} \\
\text { where } \alpha=\frac{4 D_{s^{t} L S}}{\lambda^{2}}
\end{gathered}
$$

$\boldsymbol{D}_{s}$ is the solute diffusion coefficient in the solid region, $t_{L S}$ is local solidification time and $\lambda$ is the dendritic arm spacing. In addition to solid back-diffusion, there is another phenomenon denominated: solidification kinetics must be considered, as far as it can influence microsegregation profiles. Although the influence of thermal variables, such as temperature gradient and cooling rate on the dendritic arm spacings has been studied, the literature still is scarce on research about the effects of solidification speed on the microsegregation profiles, Ferreira et al. ${ }^{4}$, Baptista et al. ${ }^{16}$ and Baptista et al. ${ }^{19}$. An equation for effective partition coefficient $\left(\boldsymbol{k}_{e f}\right)$ as a function of the solidification speed $\left(S_{S}\right)$, was proposed by Burton et al. ${ }^{27}$, eq. (5). The equilibrium partition coefficient $\left(\boldsymbol{k}_{e q}\right)$ in the Scheil and Clyne and Kurz equation, can be replaced by this effective distribution coefficient $\left(\boldsymbol{k}_{e f}\right)$.

$$
k_{e f}=\frac{k_{e q}}{k_{e q}+\left(1-k_{e q}\right) e^{\left(\frac{S S^{s}}{D l}\right)}}
$$

where $\lambda$ diffusion layer thickness of the segregated solute ahead the solid/liquid interface, $\mathrm{D}_{l}$ is the liquid solute diffusivity and $\boldsymbol{S}_{S}$ represents the solidification speed. Diffusion length scale $(\lambda)$ depends on the solidification speed, the viscosity of the liquid region and the stirring conditions ahead the solid/liquid interface, and can vary between $10^{-6}$ to $10^{-3} \mathrm{~m}$, as discussed by Meza et al. ${ }^{28}$. As proposed by Ferreira et al. ${ }^{29}$, the value of this parameter must be represented as a function of solidification speed $\left(\delta=f\left(\mathrm{~S}_{\mathrm{S}}\right)\right)$ for each position along the ingot, these results are showed in Table 1 .

\section{Results and Discussion}

Fig. 2 shows the phase diagram of the alloy system investigated, calculated by thermodynamics software ${ }^{30}$. For $\mathrm{Cu}-20$ wt.\% Sn alloy, during cooling the solidification begins at liquidus temperature of $874.3^{\circ} \mathrm{C}$, as indicated in Fig. 2, emphasizing the liquid-solid transformation region.

Generally, solidification leads to two types of grain morphologies, i.e., columnar and equiaxed grains. During nucleation in an undercooled melt, growth is generally equiaxed, i.e., it proceeds equally in all directions and so does the heat flux. In this way, dendritic morphologies form a polycrystalline solid with randomly oriented grains. On the other hand, the macrostructure is known as columnar if the heat flux is unidirectionally oriented, at least locally. In the first case, heat flows from the crystal into the undercooled melt, while that the second case of directional growth the heat flows from the superheated melt into the cooler solid. In equiaxed growth the solid/liquid interface is morphologically unstable, favoring dendritic grains, while in columnar growth, depending on the local growth conditions, one may grow planar, cellular or dendritic morphologies. The 
Table 1. Diffusion layer thickness $(\delta)$ for different positions $(P)$ in ingot.

\begin{tabular}{lccccccc}
\hline $\boldsymbol{P}(\boldsymbol{m m})$ & 5 & 10 & 15 & 20 & 35 & 45 & 60 \\
$\boldsymbol{\delta}(\boldsymbol{m})$ & $4.5 \times 10^{-6}$ & $5.7 \times 10^{-6}$ & $6.5 \times 10^{-6}$ & $7.2 \times 10^{-6}$ & $8.7 \times 10^{-6}$ & $9.5 \times 10^{-6}$ & $1.1 \times 10^{-5}$ \\
\hline
\end{tabular}

Table 2. Physical properties ${ }^{1,12}$.

\begin{tabular}{lcc} 
Solute & $\mathbf{D}_{1}\left[\mathrm{~m}^{2} / \mathrm{s}\right]$ & $\mathbf{D}_{\mathrm{s}}\left[\mathrm{m}^{2} / \mathrm{s}\right]$ \\
$\mathrm{Sn}$ & $3.23 \times 10^{-9}$ & $4.74 \times 10^{-13}$ \\
\hline
\end{tabular}

transition from columnar to equiaxed (CET) takes place when nucleation of equiaxed grains occurs in the liquid ahead of the columnar zone. Fig. 3 shows the unidirectionally solidified macrostructure of $\mathrm{Cu}-20 \mathrm{wt} . \%$ Sn alloy, indicating the predominance of elongated columnar grains, aligned approximately parallel to the direction of the heat flow. One can see that approximately eighty-five percent of the ingot is composed of a columnar dendritic macrostructure, after which it is observed a small region of equiaxed dendritic grains close to the its top.

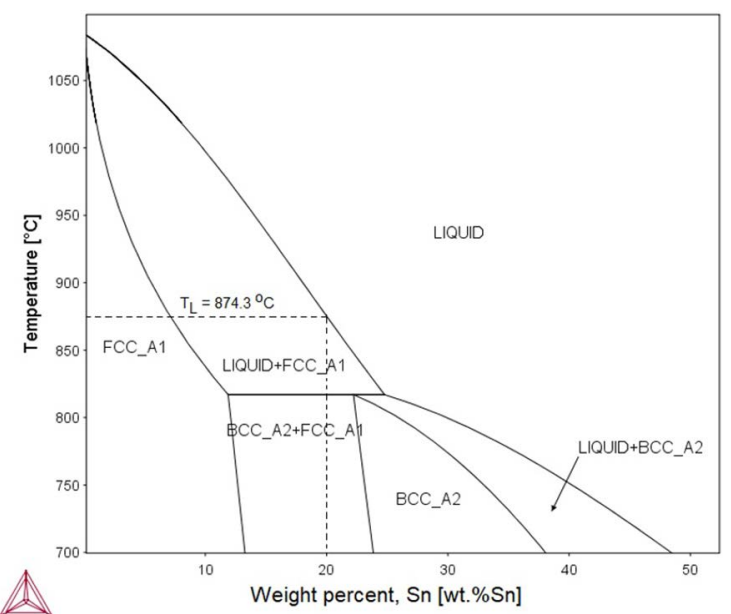

Figure 2. Phase diagram of $\mathrm{Cu}-\mathrm{Sn}$ system calculated by ThermoCalc Software ${ }^{31}$.

The cooling curves experimentally measured by the thermocouples placed along the longitudinal axis of the casting are given in Fig. 4.

One of the thermocouples was placed $5 \mathrm{~mm}$ from mold base $(0 \mathrm{~mm})$ and the others were positioned at 10, 15, 20, 35,45 and $60 \mathrm{~mm}$ away from mold base. These cooling curves are very similar to those presented by Baptista et al. ${ }^{16}$ and Sales et al. ${ }^{31}$, showing small plateaux close to liquidus temperature. The pouring temperature was setup about 1000 ${ }^{\circ} \mathrm{C}$, one can see that temperature profiles decrease faster at regions closer to the water-cooled bottom. The cooling curves then gradually dwindles toward completion of local solidification. The thermal parameters were calculated from the cooling curves experimentally measured, i.e., solidification speed $\left(\boldsymbol{S}_{S}\right)$ and cooling rate $\left(\mathrm{C}_{R}\right)$. The solidification speed $\left(\boldsymbol{S}_{S}\right)$ is experimentally calculated as $\mathrm{S}_{\mathrm{S}}=\mathrm{dP} / \mathrm{dt}$, as suggested by Baptista et al. ${ }^{19}$, while the cooling rate $\left(\mathrm{C}_{R}\right)$ at each

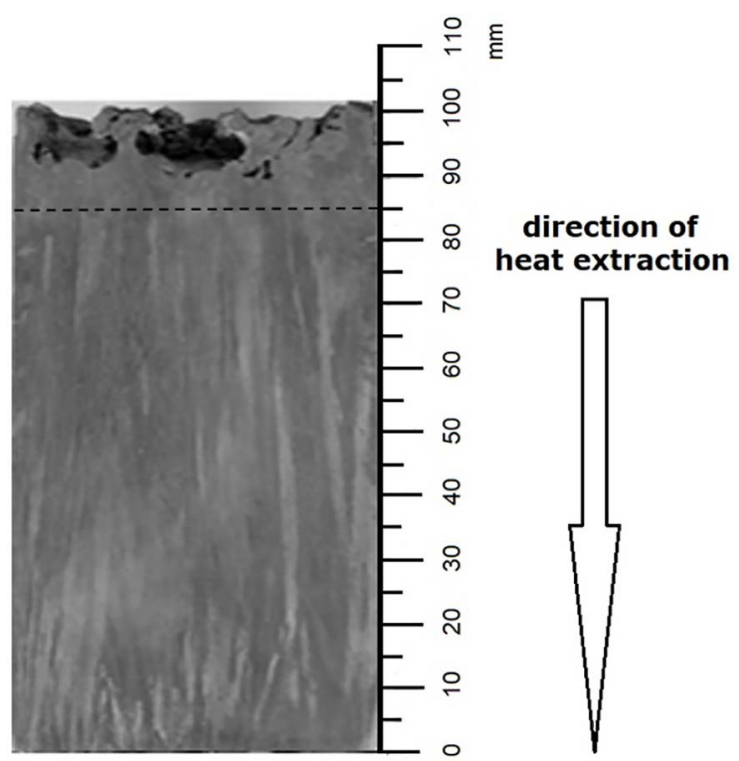

Figure 3. As-cast grain macrostructure of the $\mathrm{Cu}-20 \mathrm{wt} . \% \mathrm{Sn}$ alloy.

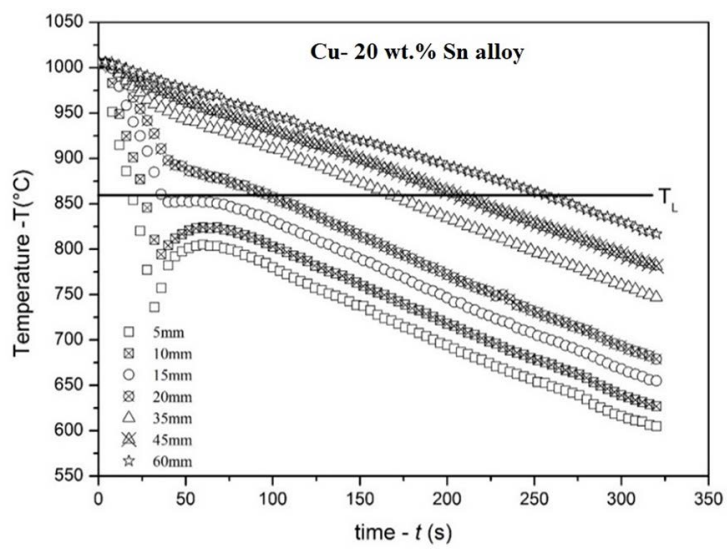

Figure 4. Temperature profiles for each position of the thermocouples.

thermocouples position is calculated as $C_{R}=d T / d t$, as showed in the literature by Baptista et al. ${ }^{16}$ and Sales et al. ${ }^{31}$. With the cooling curves, the solidification front position curve was determined as a function of time by regression of the experimental data, as shown in Figure 5. For each of the seven measurement points, the moment at which the material started to solidify was determined by the threshold observed in the corresponding temperature $\mathrm{x}$ time curve. From this function the solidification speed $\left(\boldsymbol{S}_{S}\right)$ was determined as a function of time by calculating the derivative of the same in relation to the time. Figure 5 also shows these results.

Regrouping both equations, an equation of the solidification speed as a function of the distance from the base, can be obtained, as shown in Figure 6. The solidification speed $\left(\mathrm{S}_{\mathrm{S}}\right)$ 


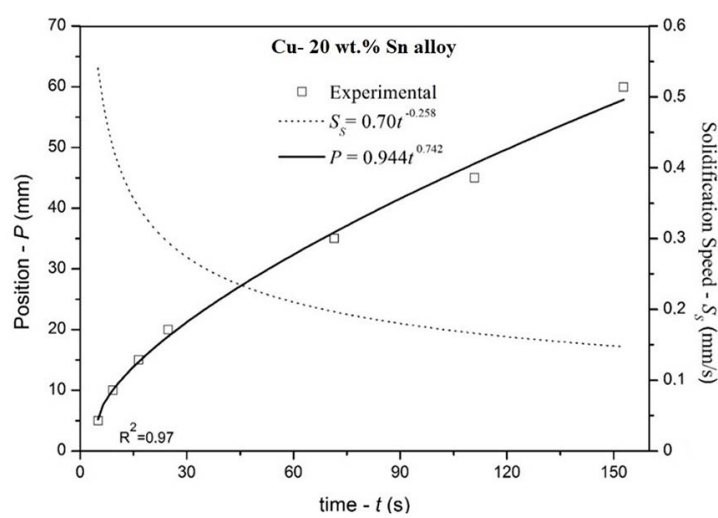

Figure 5. Position of liquidus temperature $(\mathrm{P})$ and Solidification Speed $\left(\mathbf{S}_{S}\right)$ versus time.

decrease very fast in the regions close to the cooling base and becomes almost constant with the increase in distance from its base. This can be explained by the increase in layer thickness of solidified material as the solidification proceeds.

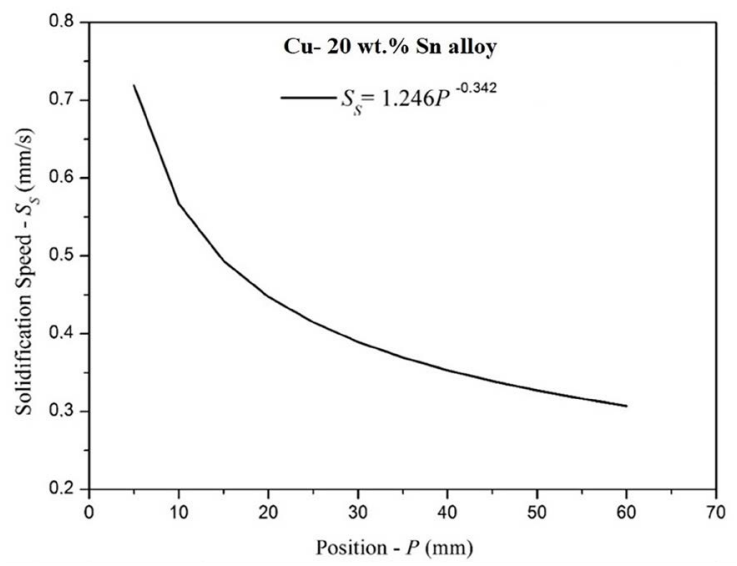

Figure 6. Solidification speed $\left(\mathbf{S}_{S}\right)$ versus Position $(\mathrm{P})$.

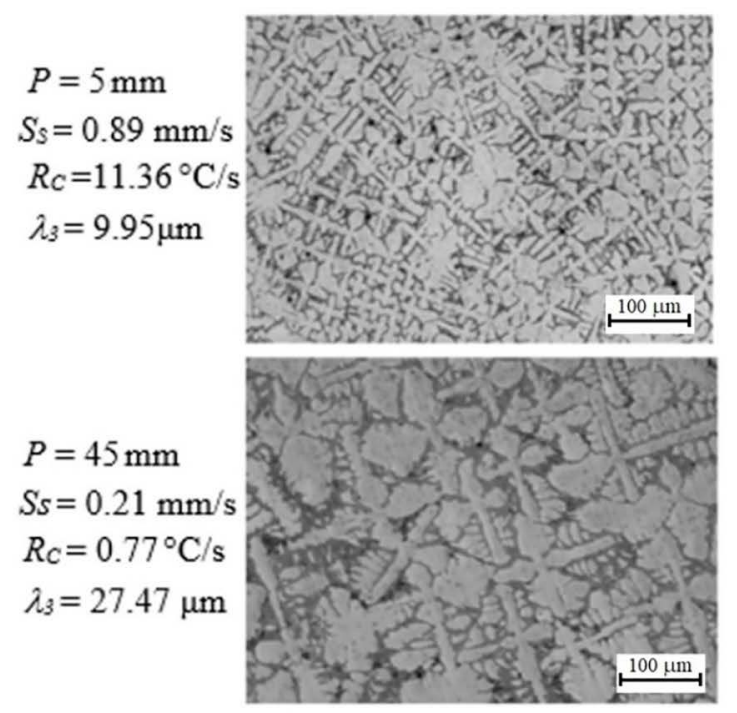

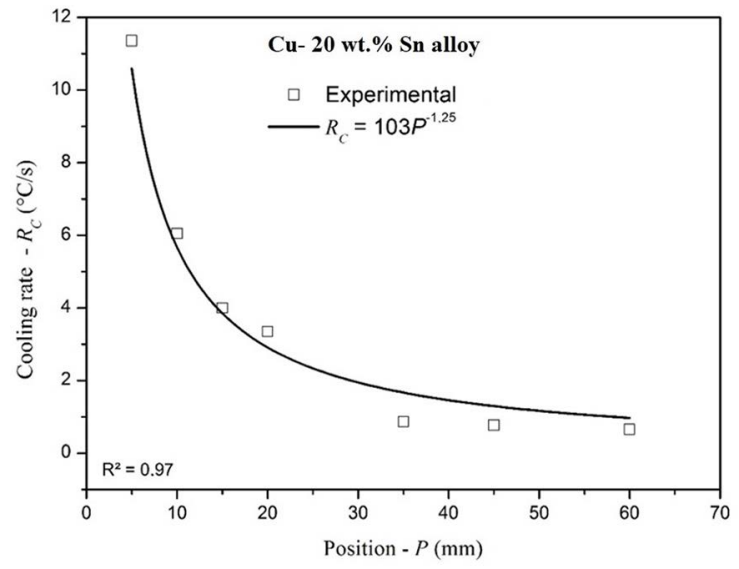

Figure 7. Cooling rate $\left(\mathrm{R}_{C}\right)$ versus Position $(\mathrm{P})$.

From the cooling curves of Figure 4, the cooling rate $\left(\boldsymbol{R}_{C}\right)$ was also determined, approaching the derivative of the temperature with respect to the time at the moment of the beginning of the solidification at each measurement point. The results are shown in Figure 7. It can be observed a similar behavior for the cooling rate $\left(\boldsymbol{R}_{C}\right)$ as compared with the solidification speed $\left(\boldsymbol{S}_{S}\right)$, (Figure 6).

Figure 8 shows the typical dendrites visualized at positions $5,15,45$ and $60 \mathrm{~mm}$ with a 50X magnification. At position $5 \mathrm{~mm}$, which is closer to the cooled plate and therefore has a higher cooling rate (estimated in Figure 7 at $11.36{ }^{\circ} \mathrm{C} / \mathrm{s}$ ), it has a finer dendritic structure than at position $60 \mathrm{~mm}$, the furthest from the cooling plate, and therefore with the lowest cooling rate (estimated in Figure 7 at $0.66{ }^{\circ} \mathrm{C} / \mathrm{s}$ ) where the dendritic structure is coarser.

Tertiary dendrite spacing $\left(\lambda_{3}\right)$ were measured at all monitored points and correlated with the cooling rate $\left(\boldsymbol{R}_{C}\right)$. Figure 9 shows the effect of cooling rate $\left(\boldsymbol{R}_{C}\right)$ on dendrite spacing. 


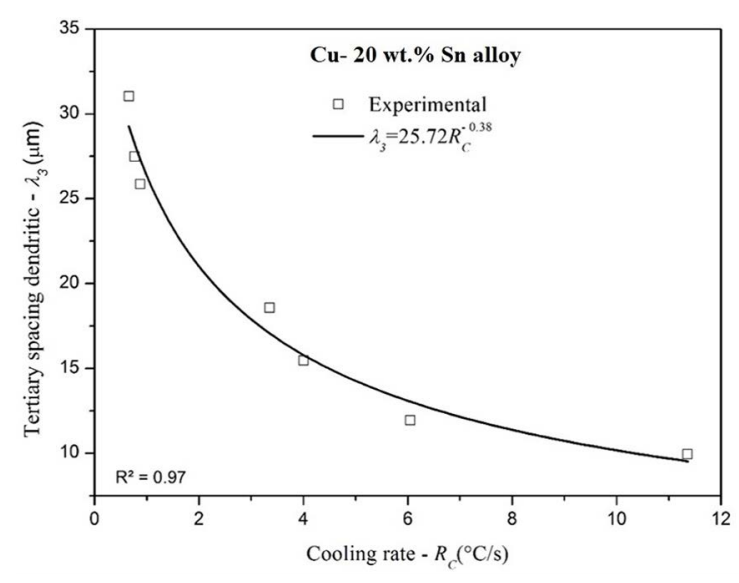

Figure 9. Tertiary dendritic spacing $\left(\lambda_{3}\right)$ versus cooling rate $\left(\mathrm{R}_{C}\right)$.

The resulting curve is in agreement with the literature data $^{19,24}$ and shows the strong influence of the cooling rate on the dendritic spacing. This effect translates to the microstructure growth, i.e., high values of $\boldsymbol{R}_{C}$ near the mold bottom, favors a more refined microstructure and low values of said thermal variable close to the top of the castings, contribute effectively to a coarser microstructure. The Vickers microhardness was also measured at all monitored points. The microhardness profile along the casting is showed in Figure 10, one can see a difference on Vickers microhardness values with the position of casting. As expected, in regions close to the cooling plate, an improvement in microhardness is observed, it is due to higher cooling rates in that regions. The said mechanical property increases from 157 to $165 \mathrm{HV}$, which confirms an increase of about $5 \%$ in microhardness.

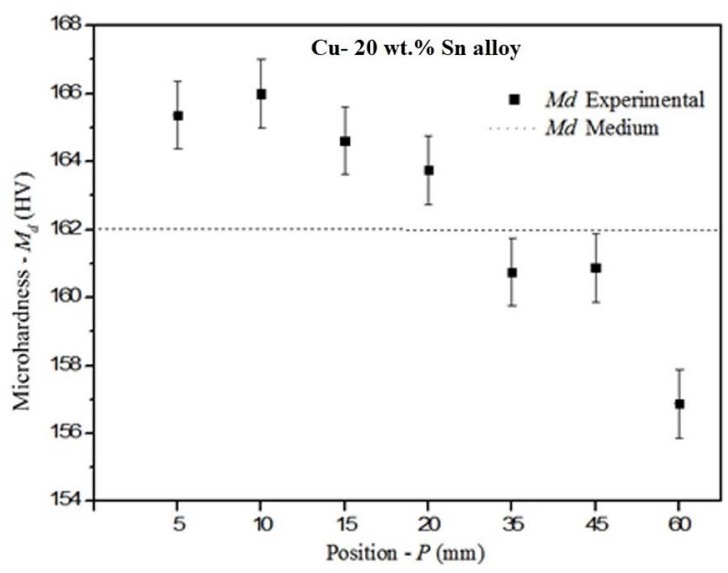

Figure 10. Microhardness $\left(\mathrm{M}_{d}\right)$ versus Position $(\mathrm{P})$.

It can be noted in Fig. 11, that microhardness is influenced by the cooling rate, which is evidenced by the experimental law $\left(M_{d}=160 R_{C}^{0.019}\right)$. High cooling rates were responsible for an improvement in microhardness at regions close to the cooling plate.

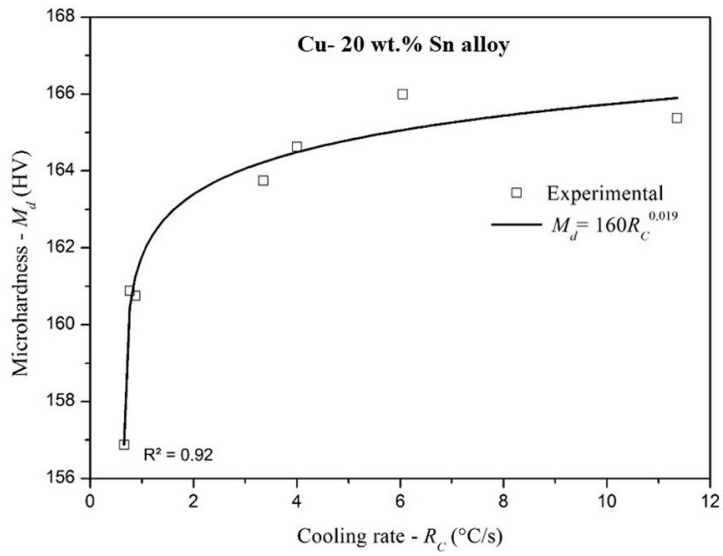

Figure 11. Microhardness $\left(\mathrm{M}_{d}\right)$ versus Cooling rate $\left(\mathrm{R}_{C}\right)$.

Figure 12 shows the microsegregation profiles from the central part of the dendritic arm to the limit of the interdendritic regions, which were experimentally determined for different positions along the ingot. In that Figure, microsegregation profiles calculated by Scheil's analytical equation are plotted for comparison purposes.

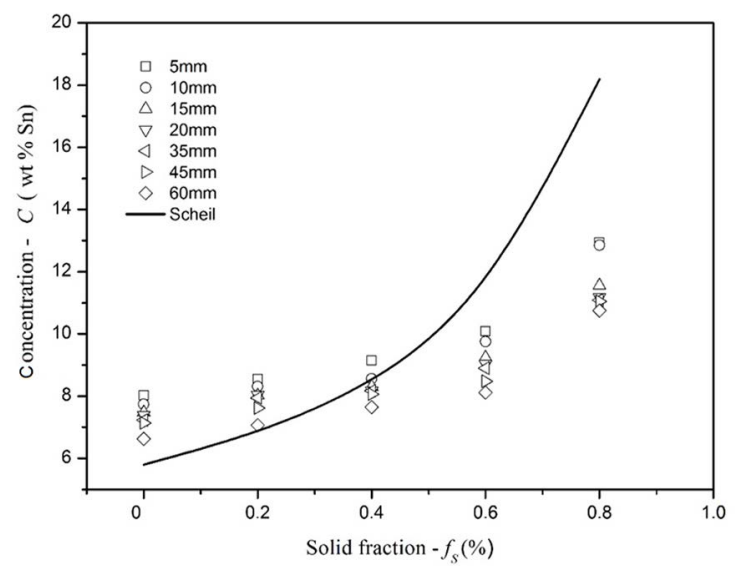

Figure 12. Concentration $(\mathrm{C})$ versus Solid fraction $\left(\mathrm{f}_{S}\right)$.

One can see a deviation between the curves shown in Figure 12. The Scheil's equation using equilibrium partition coefficient $\left(\boldsymbol{k}_{e q}\right)$, does not adequately describe the experimental behavior for microsegregation profiles. This is due to the fact that high solidification speeds favor deviation from the equilibrium conditions during the solidification process. In order of improving the prediction capability of microsegregation profiles, the effective partition coefficient $\left(\boldsymbol{K}_{e f}\right)$ is considered in present work. The eq. (5) has been used to create a plot of effective partition coefficient $\left(\boldsymbol{S}_{S}\right)$ versus solidification speed $\left(\boldsymbol{S}_{S}\right)$. In order to found an experimental equation of the effective partition coefficient $\left(\boldsymbol{k}_{e f}\right)$ as a function of solidification speed $\left(\boldsymbol{S}_{S}\right)$, a curve fitting technique have been adopted on points shown in Fig. 13. 


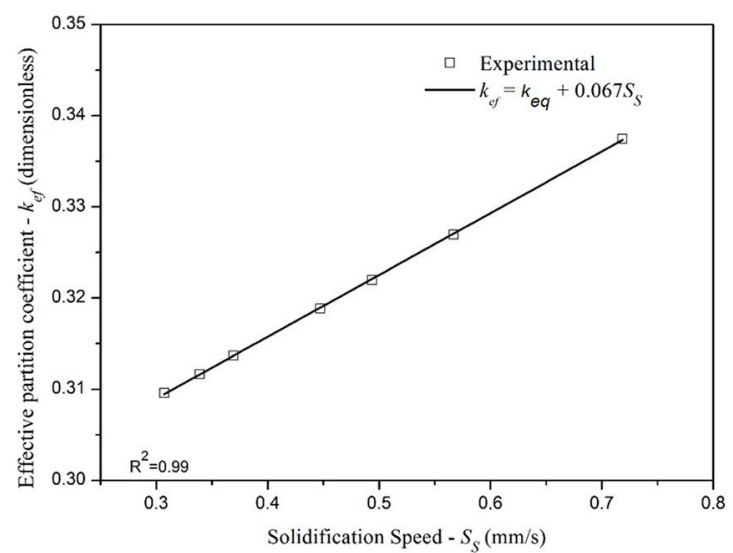

Figure 13. Effective Partition Coefficient $\left(\mathrm{k}_{e f}\right)$ versus Solidification speed $\left(\mathbf{S}_{S}\right)$.

It is important to highlight that the experimental equation shown in Fig. 13 have been derived for a solidification speed range from 0.19 to $0.89 \mathrm{~mm} / \mathrm{s}$ and that for higher solidification speed $\left(\boldsymbol{S}_{S}\right)$ a tendency to approach $\boldsymbol{k}_{e f}=1$ will exist, since Eqs. 1 and 2 are operative between equilibrium partition coefficient $\left(\boldsymbol{k}_{e q}\right)$ and 1. Despite the tremendous importance of the experimental laws representing microhardness (Md) as a function of cooling rate $\left(\boldsymbol{R}_{C}\right)$ or effective partition coefficient $\left(\boldsymbol{k}_{e f}\right)$ as a function of solidification speed $\left(\boldsymbol{S}_{S}\right)$ for $\mathrm{Cu}-\mathrm{Sn}$ alloys, there is still is no available in the open literature, experimental laws similar to the ones showed in this present work. The microsegregation profiles of Sn using the Scheil and Clyne-Kurz equation are shown in Fig. 14a and $14 \mathrm{~b}$, respectively. The profiles were obtained using the effective partition coefficient $\left(\boldsymbol{k}_{e f}\right)$ as a function of solidification speed $\left(\boldsymbol{S}_{S}\right)$. However, results shown in Fig. 14a-b display weak agreement between the numerical and experimental data, considerable discrepancies can be observed at higher solid fraction $\left(\mathrm{f}_{S}>0.4\right)$.

The calculated results by both equations overestimate the experimental data for $\mathbf{f}_{S}>0.4$. These discrepancies between results, can arise from micro-scale phenomena as solid backdiffusion and interdiffusion during cooling and coarsening, Baptista et al. ${ }^{19}$. In order of improving the prediction capability of concentration profiles of $\mathrm{Sn}$, an experimental equation is considered in present work $^{28}$, which is based on a best-fit curve to the experimental data, and is given by:

$$
C=C_{0} k_{e f}+a e^{b f s}
$$

where $\mathrm{a}$ and $\mathrm{b}$ are experimental constants. The Fig. 15 shows empirical equation here considered, with effective partition coefficient $\left(\boldsymbol{k}_{e f}\right)$ as a function of solidification speed $\left(\boldsymbol{S}_{S}\right)$. The results shown in Fig. 15 display excellent agreement between the calculated and experimental data.

The calculated microsegregation from the center of dendritic arm to the midpoint of the interdendritic region

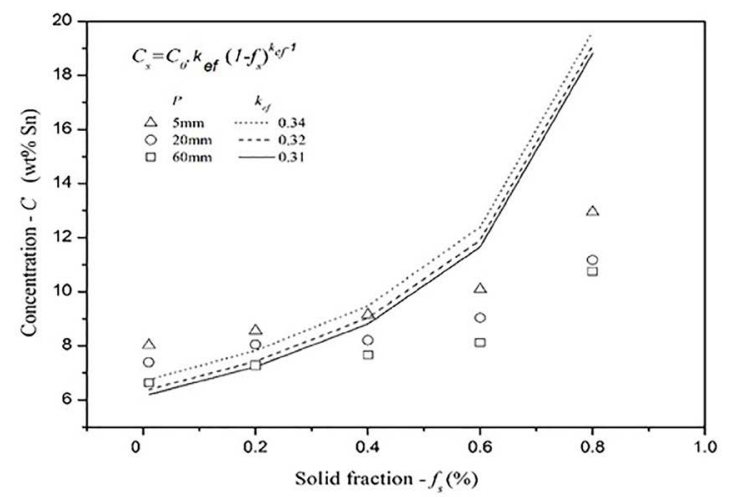

(a)

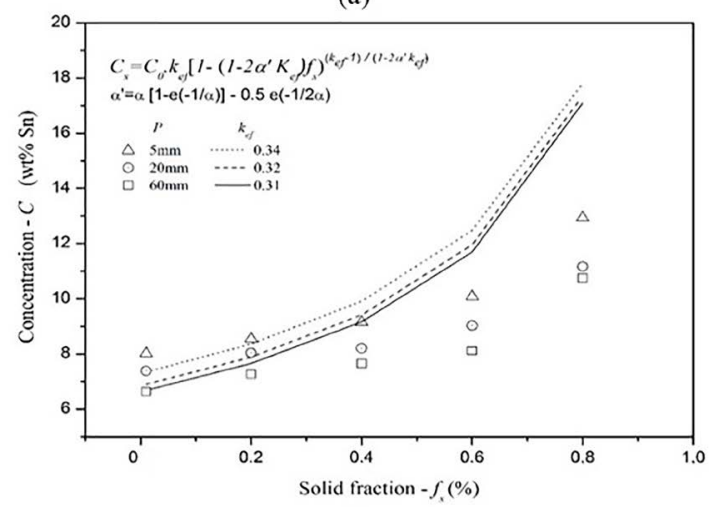

(b)

Figure 14. Estimated microsegregation using: a) Scheil and b) Clyne-Kurz equation.

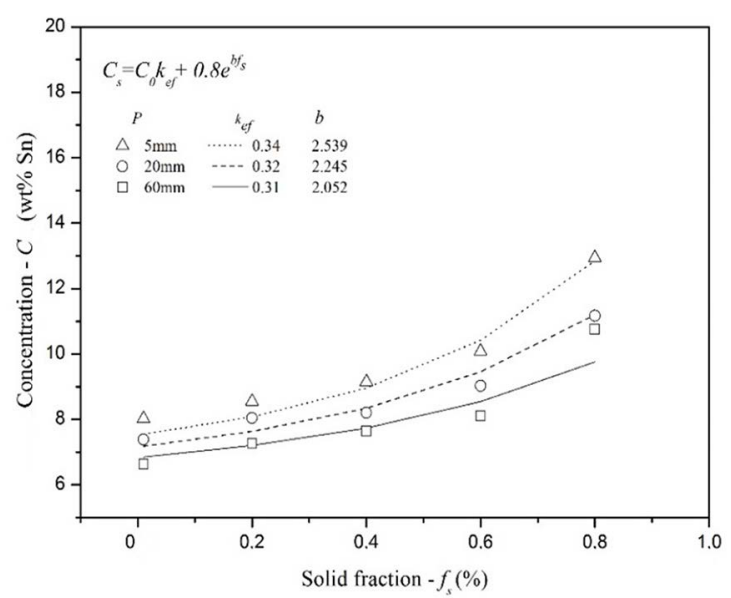

Figure 15. Comparison between measured microsegregation profiles and predictions by the experimental equation.

between adjacent arms, adjusted well to the experimental data. It seems that the experimental constant a depends of alloy system and it was found to be 0.8 , while the constant $\mathrm{b}$ is associated to the solidification speed $\left(\boldsymbol{S}_{S}\right)$, i.e., for an alloy its value increases with the increase in solidification speed $\left(\boldsymbol{S}_{S}\right)$. 


\section{Conclusions}

The effects of solidification speed $\left(\boldsymbol{S}_{S}\right)$ and cooling rate $\left(\boldsymbol{R}_{C}\right)$ on the microstructure features and $\mathrm{Sn}$ microsegregation has been experimentally investigated on $\mathrm{Cu}-20$ wt.\% Sn alloy. It was shown that a quite complex dendritic arrangement along the entire length of casting, giving rise to well-defined tertiary dendritic arm spacings $\left(\boldsymbol{\lambda}_{3}\right)$. The increase in the solidification speed $\left(\boldsymbol{S}_{S}\right)$ and cooling rate $\left(\boldsymbol{R}_{C}\right)$ induce the decrease on the tertiary dendrite arm spacing. As expected, cooling rate is responsible for an improvement in microhardness $\left(\mathrm{M}_{d}\right)$, i.e., the mechanical property improves from 157 to $165 \mathrm{HV}$, which confirms an increase of about $5 \%$. The microsegregation profiles experimentally determined between adjacent tertiary dendritic arm spacing revealed that said profiles increase gradually from center of dendritic arm toward the center of the interdendritic region. The effect of solidification speed on the microsegregation profiles of $\mathrm{Sn}$ has been investigated via Scheil and Clyne-Kurz equation with incorporation of solidification speed $\left(\boldsymbol{S}_{S}\right)$ into effective partition coefficient, which has been calculated for the range of solidification speed $\left(\boldsymbol{S}_{S}\right)$ from 0.19 to $0.89 \mathrm{~mm} / \mathrm{s}$. However, results obtained by Scheil and Clyne-Kurz equation yielded discrepancies from the experimental data. For this reason, an experimental equation is considered here, which is based on a best-fit curve to the experimental data. The microsegregation profiles calculated by the experimental equation was shown an excellent agreement to the experimental data. The results obtained here confirm the effect of solidification speed $\left(\boldsymbol{S}_{S}\right)$ on the $\mathrm{Sn}$ rejected from the solid to liquid region during solidification process.

\section{Acknowledgments}

The authors acknowledge the support provided by IME (Instituto Militar de Engenharia) through its Materials and Mechanical Engineering Section, the Foseco Company and the financial support provided by CAPES (Coordenação de Aperfeiçoamento de Pessoal de Nível Superior).

\section{References}

1. Kohler F, Campanella T, Nakanishi S, Rappaz M. Application of single pan thermal analysis of $\mathrm{Cu}-\mathrm{Sn}$ peritectic alloys. Acta Materialia. 2008;56(7):1519-1528. DOI: doi.org/10.1016/j. actamat.2007.12.006

2. Mardare CC, Hassel AW. Influence of cooling speed on the solidification of a hyper-eutectic Cu-Sn alloy. Physica Status Solidi A. 2012;209(5):825-831. DOI: doi.org/10.1002/ pssa.201100617

3. Valloton J, Wagnière JD, Rappaz M. Competition of the primary and peritectic phases in hypoperitectic $\mathrm{Cu}-\mathrm{Sn}$ alloys solidified at low speed in a diffusive regime. Acta Materialia. 2012;60(9):38403848. DOI: doi.org/10.1016/j.actamat.2012.03.030
4. Ferreira AF, Paradela KG, Felipe Junior P, Alcântara Junior Z, Garcia A. Phase-Field Simulation of Microsegregation and Dendritic Growth During Solidification of Hypoeutectic Al-Cu alloys. Materials Research. 2017;20(2):423-429. DOI: dx.doi. org/10.1590/1980-5373-mr-2016-0194

5. Tang J, Xue X. Numerical simulation of multi-grain structure and prediction of microsegregation in binary $\mathrm{Ni}-\mathrm{Cu}$ alloy under isothermal conditions. Materials Science and Engineering: A. 2009;499(1-2):64-68. DOI: doi.org/10.1016/j. msea.2007.11.114

6. Kasperovich G, Volkmann T, Ratke L, Herlach D. Microsegregation during Solidification of an Al-Cu Binary Alloy at Largely Different Cooling Rates ( 0.01 to $20.000 \mathrm{~K} / \mathrm{s})$ : Modeling and Experimental Study. Metallurgical and Materials Transactions A. 2008;39(5):1183-1191. DOI: doi.org/10.1007/s11661-0089505-6

7. Spinelli JE, Ferreira IL, Garcia A. Influence of melt convection on the columnar to equiaxed transition and microstructure of downward unsteady-state directionally solidified $\mathrm{Sn}-\mathrm{Pb}$ alloys. Journal of Alloys and Compounds. 2004;384(1-2):217-226. DOI: doi.org/10.1016/j.jallcom.2004.04.098

8. Doré X, Combeau H, Rappaz M. Modelling of microsegregation in ternary alloys: application to the solidification of Al-Mg-Si. Acta Materialia. 2000;48(15):3951-3962. DOI: doi.org/10.1016/ S1359-6454(00)00177-4

9. Turkeli A. Approximate Analytical Models for Microsegregation Considering the Effect of Dendrite Arm Coarsening. Materials Science Forum. 2006;508:449-454. DOI: doi.org/10.4028/www. scientific.net/MSF.508.449

10. Du Q, Eskin DG, Jacot A, Katgerman L. Two-dimensional modeling and experimental study on microsegregation during solidification of an Al-Cu binary alloy. Acta Materialia. 2007;55(5):15231532. DOI: doi.org/10.1016/j.actamat.2006.10.035

11. Ferreira AF, Ferreira LO. Microsegregation in Fe-C-p ternary alloys using a phase-field model. Journal of the Brazilian Society of Mechanical Sciences and Engineering. 2009;31(3):173-180. DOI: dx.doi.org/10.1590/S1678-58782009000300002

12. Kumoto EA, Alhadeff RO, Martorano MA. Microsegregation and dendrite arm coarsening in tin bronze. Materials Science and Technology. 2002;18(9):1001-1006. DOI: doi. org/10.1179/026708302225005882

13. Yan X, Xie F, Chu M, Chang YA. Microsegregation in Al-4.5Cu wt.\% alloy: experimental investigation and numerical modeling. Materials Science and Engineering: A. 2001;302(2):268-274. DOI: doi.org/10.1016/S0921-5093(00)01825-6

14. Xie F, Yan X, Ding L, Zhang F, Chen S, Chu MG, et al. A Study of microstructure and microsegregation of aluminum 7050 alloy. Materials Science and Engineering: A. 2003;355(1-2):144-153. DOI: doi.org/10.1016/S0921-5093(03)00056-X

15. Avazkonandeh-Gharavol MH, Haddad-Sabzevar M, Fredriksson H. Effect of partition coefficient on microsegregation during solidification of aluminium alloys. International Journal of Minerals, Metallurgy, and Materials. 2014;21(10):980-989. DOI: doi.org/10.1007/s12613-014-0999-1 
16. Baptista LAS, Paradela KG, Ferreira IL, Garcia A, Ferreira AF. Experimental study of the evolution of tertiary dendritic arms and microsegregation in directionally solidified Al$\mathrm{Si}-\mathrm{Cu}$ alloys castings. Journal of Materials Research and Technology. 2019;8(1):1515-1521. DOI: https://doi.org/10.1016/j. jmrt.2018.05.021

17. Kohler F, Germond L, Wagnière JD, Rappaz M. Peritectic solidification of $\mathrm{Cu}-\mathrm{Sn}$ alloys: Microstructural competition at low speed. Acta Materialia. 2009;57(1):56-68. DOI: doi. org/10.1016/j.actamat.2008.08.058

18. Stier M, Rettenmayr M. Microstructural evolution in near-metatectic Cu-Sn alloys. Journal of Crystal Growth. 2008;311(1):137-140. DOI: doi.org/10.1016/j.jcrysgro.2008.10.033

19. Baptista LAS, Ferreira AF, Paradela KG, da Silva DM, de Castro JA. Experimental Investigation of Ternary Al-Si-Cu Alloy Solidified with Unsteady-State Heat Flow Conditions. Materials Research. 2018;21(3):e20170565. DOI: dx.doi. org/10.1590/1980-5373-mr-2017-0565

20. Yan X, Chen S, Xie F, Chang YA. Computational and experimental investigation of microsegregation in an al-rich Al-Cu-Mg-Si quaternary alloy. Acta Materialia. 2002;50(9):2199-2207. DOI: doi.org/10.1016/S1359-6454(01)00431-1

21. Gündüz M, Çadirh E. Directional solidification of aluminium-copper alloys. Materials Science and Engineering: A. 2002;327(2):167185. DOI: doi.org/10.1016/S0921-5093(01)01649-5

22. Magnusson T, Arnberg L. Density and solidification shrinkage of hipoeutectic aluminum-silicon alloys. Metallurgical and Materials Transactions A. 2001;32(10):2605-2613. DOI: doi. org/10.1007/s11661-001-0050-9

23. Voort GFV. Metallography: Principles and Practice. Materials Park: ASM International; 1984.
24. Sá F, Rocha OL, Siqueira CA, Garcia A. The effect of solidification variables on tertiary dendrite arm spacing in unsteady-state directional solidification of $\mathrm{Sn}-\mathrm{Pb}$ and $\mathrm{Al}-\mathrm{Cu}$ alloys. Materials Science and Engineering: A. 2004;373(1-2):131-138. DOI: doi. org/10.1016/j.msea.2004.02.010

25. Kattamis TZ, Flemings MC. Dendrite morphology, microsegregation and homogenization of low-alloy steel. Transactions of the Metallurgical Society of AIME. 1965;223:992-999.

26. Chalmers B. Principles of Solidification. New York: John Wiley \& Sons; 1964.

27. Burton JA, Prim RC, Slichter WP. The Distribution of Solute in Crystals Grown from the Melt. Part I. Theoretical. The Journal of Chemical Physics. 1953;21(11):1987-1990. DOI: https://doi. org/10.1063/1.1698728

28. Meza ES, Bertelli B, Goulart PR, Cheung N, Garcia A. The effect of the growth rate on microsegregation: Experimental investigation in hypoeutectic $\mathrm{Al}-\mathrm{Fe}$ and $\mathrm{Al}-\mathrm{Cu}$ alloys directionally solidified. Journal of Alloys and Compounds. 2013;561:193200. DOI: doi.org/10.1016/j.jallcom.2013.01.180

29. Ferreira IL, Moreira ALS, Aviza JAS, Costa TA, Rocha OL, Barros AS, et al. On an expression for the growth of secondary dendrite arm spacing during non-equilibrium solidification of multicomponent alloys: Validation against ternary aluminum-based alloys. Journal of Manufacturing Processes. 2018;35:634-650. DOI: doi.org/10.1016/j.jmapro.2018.08.010

30. Thermo-Calc Software AB. Solna.

31. Sales RC, Felipe Junior P, Paradela KG, Garção WJL, Ferreira AF. Effect of Solidification Processing Parameters and Silicon Content on the Dendritic Spacing and Hardness in Hypoeutectic Al-Si Alloys. Materials Research. 2018;21(6):e20180333. DOI: doi.org/10.1590/1980-5373-MR-2018-0333 